\title{
Refractory Intermediate Risk Acute Myeloid Leukemia
}

National Cancer Institute

\section{Source}

National Cancer Institute. Refractory Intermediate Risk Acute Myeloid Leukemia. NCI

Thesaurus. Code C162458.

The reemergence of intermediate risk acute myeloid leukemia after a period of remission. 